\title{
Height, weight, and body mass index association with breast cancer risk in Iraqi Kurdish women
}

\author{
Sherko Abdullah Molah Karim*1, Hawar Hasan Ali Ghalib²,3, Fattah Hama Rahim Fattah ${ }^{3}$, Mohammed Ibrahim \\ Mohialdeen Gubari ${ }^{4}$, Aween Baiz Majeed ${ }^{5}$ \\ ${ }^{1}$ Department of Surgery, Ranya General Hospital in Ranya province, Sulaimanyah Governorate, Iraq \\ ${ }^{2}$ Department of Surgery, Shar Hospital, Sulaimanyah, Iraq \\ ${ }^{3}$ School of Medicine, Faculty of Medical Science, Sulaimani University, Iraq \\ ${ }^{4}$ Community Health Department, Sulaimani polytechnic University, Iraq \\ ${ }^{5}$ Department of General Surgery, Teaching Hospital of Sulaimanyah, Iraq
}

Received: June 12, 2015

DOI: $10.5430 /$ css.v1n1p1
Accepted: July 26, 2015

Online Published: August 8, 2015

\begin{abstract}
Background: To our knowledge, there is no international publication on association of body mass index (BMI) and breast cancer in the Iraqi Kurdish women. The aims of this study are to identify the correlation of height, weight, and BMI with breast cancer, as well as, the relationship of BMI with pre- and postmenopausal women with breast cancer among Iraqi Kurds.

Materials and methods: This retrospective case-control study was performed in Sulaimanyah governorate (North of Iraq). Data were collected on socio-demographic characteristics, anthropometric measures and menopausal status of (454) patients with breast cancer who were seeking medical attention in Hewa Hematology and Oncology Hospital with collection of same information on (430) age-matched controls.

Results: There were 454 cases of breast cancer, the mean value of height was $161 \pm 6.2 \mathrm{~cm}$ compared to controls $159.3 \pm$ $5.1 \mathrm{~cm}(p<.001)$, mean weight $68.9 \pm 11.8 \mathrm{~kg}$ compared to controls $62.1 \pm 9.1 \mathrm{~kg}(p<.001)$, mean BMI $26.6 \pm 4.5 \mathrm{~kg} / \mathrm{m}^{2}$ compared to controls $24.5 \pm 3.8 \mathrm{~kg} / \mathrm{m}^{2}(p<.001)$. There was a significant statistical difference between the height of patients and controls in both pre-and postmenopausal Kurdish women. The odds ratios for breast cancer development in premenopausal women with BMI $\left(23-24.9,25-29.9\right.$, and $\left.\geq 30 \mathrm{~kg} / \mathrm{m}^{2}\right)$ were $(1.4,1.8,2.1)(p<.001)$, respectively. The odds ratios for breast cancer development in postmenopausal women for same BMI categories were $(1.7,3.2,4.0)(p<.001)$, respectively.

Conclusions: Among Iraqi Kurdish women, height, weight, and BMI are associated with increased risk of breast cancer. There is a positive association between BMI and breast cancer risk for both pre- and postmenopausal women, but the association is stronger among postmenopausal women.
\end{abstract}

Key Words: Body mass index, Breast cancer, Kurdish women, Iraq

\section{INTRODUCTION}

The breast cancer is the most common cancer in women worldwide and the commonest cause of cancer death in women. ${ }^{[1,2]}$ Body mass index (BMI, weight in kilograms divided by the square of height in meters) is a marker for general adiposity. ${ }^{[3]}$ BMI categorized into Underweight (BMI < $\left.18.5 \mathrm{~kg} / \mathrm{m}^{2}\right)$, Normal range $\left(18.5-24.9 \mathrm{~kg} / \mathrm{m}^{2}\right)$, Overweight $\left(25-30 \mathrm{~kg} / \mathrm{m}^{2}\right)$, and Obese ( BMI $\left.\geq 30 \mathrm{~kg} / \mathrm{m}^{2}\right)$ as defined by

\footnotetext{
* Correspondence: Sherko Abdullah Molah Karim; Email: sherkoabdullah@yahoo.com; Address: Department of Surgery, Ranya General Hospital in Ranya province, Sulaimanyah Governorate, Iraq. 
WHO BMI classification. ${ }^{[4]}$ There is a substantial variation in the mean body mass index across countries ${ }^{[5,6]}$ and in different religions. ${ }^{[7]}$

Unfortunately, in Iraq there are limited studies and data registry on breast cancer published internationally. Although, Iraqi women are considerably different from western women in their BMI, ethnicity, dietary lifestyle and culture, in our study we depend on Asian and western published studies on breast cancer, but this paper can be used as a basic material for the future studies which will be done in Iraq. To the best of our knowledge, there is no publication which analyzes the association of BMI and breast cancer risk among Iraqi Kurdish population. Some studies were done in Asian countries such as (China and Japan) and they have observed that there was a significant positive association of BMI with breast cancer in postmenopausal women, ${ }^{[8-10]}$ while a metaanalysis of Korean women showed that a high BMI was related to a higher incidence rate of breast cancer in both pre- and postmenopausal women. ${ }^{[11]}$ In the rest of the world (Europe, USA, Australia, and Africa) many epidemiological studies have shown that the obesity is associated with a significantly elevated breast cancer risk. ${ }^{[12,13]}$ High BMI, seems to be associated with increased breast cancer risk in postmenopausal women ${ }^{[14-17]}$ while it has slightly protective effect on premenopausal women. ${ }^{[18,19]}$ Greater BMI is associated with increased breast cancer risk in both pre- and postmenopausal African-American women. ${ }^{[20]}$ Regarding the relation of height and breast cancer, height is positively associated with risk of breast cancer. ${ }^{[21]}$ There is evidence that overweight and obesity are associated with poor survival after breast cancer diagnosis, ${ }^{[22]}$ more advanced stage of breast cancer at diagnosis in terms of tumor size, ${ }^{[23]}$ a poor breast cancer prognosis in postmenopausal women, ${ }^{[12]}$ and poor prognosis for both pre- and postmenopausal women. ${ }^{\text {[24] }}$ The relationship of breast cancer and obesity is related to high estrogen levels in postmenopausal women resulting from aromatization of androstenedione and testosterone to estrone and estradiol in adipose tissue which may activate estrogen signaling pathway. ${ }^{[25]}$ However, bioavailable estradiol is independently related to breast cancer. ${ }^{[26]}$ Recent research in molecular biology confirmed that obesity promoted cancer progression by elevating the serum estrogen level and Insulin-like growth factor which stimulated cancer progression through a growth regulatory pathway. ${ }^{[4]}$ To confirm that the association of obesity with breast cancer is related to estrogen level, some studies have observed the positive association of BMI with Estrogen Receptor (ER) positive breast cancer. $^{[27]}$ The aims of this study are to evaluate the association between height, weight, and BMI with breast cancer risk among the Iraqi Kurdish population, and, there- fore our objective is to clarify the correlation of BMI with pre- and postmenopausal women with breast cancer.

\section{MATERials AND METHOdS}

\subsection{Data collection}

This retrospective case-control study included (454) Kurdish women with histologically confirmed the diagnosis of breast cancer during 2011-2013, who were aged 20 to 82 years, in Sulaimanyah governorate (North of Iraq). The data were extracted from cancer registries department of Hewa Hematology and Oncology Hospital. This Hospital serves a population of more than 2 million people in Sulaimanyah governorate. Data were collected regarding age, sex, nationality, menopausal status and anthropometric measures of (454) incident patients at the time of diagnosis after exclusion of subjects who were Arabs, cases with missing information in their medical records, and patients who were taking oral contraceptive pills. Regarding the controls, a structured questionnaire was used to obtain data including information on socio-demographic characteristics, anthropometric measures, and menopausal status. Interviews were conducted by senior house officer of general surgery to obtain information after taking oral informed consent from the age-matched controls, which were selected among patients admitted to Accident and Emergency Hospital of Sulaimanyah for a wide spectrum of acute surgical conditions and trauma, without history of breast cancer and documented cancer in other sites which may affect the BMI. Their height and weight were measured by a senior house officer of general surgery who also completed the questionnaires. In both, cases and controls, women who have stopped menstrual cycles for more than 6 months without taking hormonal medications were regarded as post-menopause while peri-menopausal women were excluded.

\subsection{Data analysis}

This retrospective case-control analysis was restricted to Kurdish women in Iraq, we intended to assess the potential correlation between BMI and breast cancer. The predictor variable of this study was BMI which was calculated by using a standard formula: body weight $(\mathrm{kg}) /$ height $\left(\mathrm{m}^{2}\right)$. The statistical analysis was performed from two professional statisticians using (SPSS version 22) statistical package. We analyzed the association between breast cancer and BMI at the beginning, then the correlation of BMI and breast cancer in pre- and postmenopausal women, respectively. Qualitative data were expressed as number and percentage while quantitative data were expressed as mean \pm Standard Deviation (SD). Probability Value $<.05$ was regarded as a significant statistical level. The $T$-test was used to assess statistical differences of height, weight, and BMI in studied groups. Based on the 
BMI, women were grouped into 5 categories, in which the odds ratio was calculated to find risk estimation between the groups of BMI in both pre- and postmenopausal women separately. In addition, multiple logistic regression analysis was carried out to estimate odds ratios for developing breast cancer and $95 \%$ confidence intervals of variables. The second BMI category was used as a reference category.

\section{Results}

In all, 454 Kurdish women with breast cancer and 430 controls were studied, the overall mean value of height was $161 \pm 6.2 \mathrm{~cm}$ compared to controls $159.3 \pm 5.1 \mathrm{~cm}(p<$ $.001)$, mean weight $68.9 \pm 11.8 \mathrm{~kg}$ compared to controls $62.1 \pm 9.1 \mathrm{~kg}(p<.001)$, the mean of BMI in both pre- and postmenopausal women collectively was $26.6 \pm 4.5 \mathrm{~kg} / \mathrm{m}^{2}$ compared to controls $24.5 \pm 3.8 \mathrm{~kg} / \mathrm{m}^{2}(p<.001)$. There is a significant difference between the mean of patients' height, weight, and BMI and the controls.

Table 1 compares height, weight, and BMI of patients with controls in pre- and postmenopausal women. When the height mean difference between cases and control subjects was evaluated, a significant difference was observed indicating that the mean height was higher in both pre- and postmenopausal cases as compared to controls with $(p<$ $.001, p=.04)$, respectively.

Further analysis of data was performed, and the results indicated that the BMI has a positive association with both pre-and postmenopausal breast cancer among Iraqi Kurdish women. The positive association between BMI and postmenopausal breast cancer prevalence was stronger (higher odds ratio) than its association with premenopausal breast cancer risk (see Table 2, Table 3).

Table 1. Height, weight, and BMI differences between cases and controls

\begin{tabular}{|c|c|c|c|c|c|c|c|c|}
\hline \multirow[b]{2}{*}{ Items } & \multicolumn{4}{|c|}{ Premenopausal } & \multicolumn{4}{|c|}{ Postmenopausal } \\
\hline & $\begin{array}{l}\text { Cases (Mean) } \\
\pm S D\end{array}$ & $\begin{array}{l}\text { Controls (Mean) } \\
\pm S D\end{array}$ & $p$ Value & $T$-test & $\begin{array}{l}\text { Cases (Mean) } \\
\pm S D\end{array}$ & $\begin{array}{l}\text { Controls } \\
(\text { Mean) } \pm S D\end{array}$ & $p$ Value & $T$-test \\
\hline Height & $161.3 \pm 6.1$ & $159.3 \pm 5.5$ & $<.001$ & 3.9 & $160 \pm 6.3$ & $159.3 \pm 3.9$ & $=.04$ & 2 \\
\hline Weight & $69.1 \pm 10.9$ & $62.9 \pm 9.3$ & $<.001$ & 7.1 & $68.6 \pm 12.7$ & $60.3 \pm 8.4$ & $<.001$ & 6.7 \\
\hline BMI & $26.6 \pm 4.5$ & $24.8 \pm 4.1$ & $<.001$ & 4.6 & $26.6 \pm 4.7$ & $23.6 \pm 2.7$ & $<.001$ & 6.6 \\
\hline
\end{tabular}

Table 2. The Odds Ratios of breast cancer for different BMI categories in premenopausal Kurdish women

\begin{tabular}{|c|c|c|c|c|c|}
\hline \multicolumn{6}{|c|}{ Premenopausal } \\
\hline BMI Categories & Cases No. (\%) & Controls No. (\%) & Odds Ratios & 95\% CI Confidence interval & $p$ Value \\
\hline$<18.5$ & $1(0.4)$ & $24(8.2)$ & & & \multirow{6}{*}{$<.001$} \\
\hline $18.5-22.9$ & $53(21.4)$ & $89(30.4)$ & 1 Ref. & & \\
\hline $23-24.9$ & $35(14.1)$ & $41(14)$ & 1.434 & $0.815-2.522$ & \\
\hline $25-29.9$ & $107(43.1)$ & $99(33.8)$ & 1.815 & $1.173-2.808$ & \\
\hline$\geq 30$ & $52(21)$ & $40(13.7)$ & 2.183 & $1.279-3.725$ & \\
\hline Total & 248 Cases & 293 Controls & & & \\
\hline
\end{tabular}

Table 3. The Odds Ratios of breast cancer for different BMI categories in postmenopausal Kurdish women

\begin{tabular}{|c|c|c|c|c|c|}
\hline \multicolumn{6}{|c|}{ Postmenopausal } \\
\hline BMI Categories & Cases No. (\%) & Controls No. (\%) & Odds Ratios & 95\% CI Confidence interval & $p$ Value \\
\hline$<18.5$ & $0(0)$ & $2(1.5)$ & & & \multirow{6}{*}{$<.001$} \\
\hline $18.5-22.9$ & $33(16)$ & $46(33.6)$ & 1 Ref. & & \\
\hline $23-24.9$ & $48(23.3)$ & $39(28.5)$ & 1.716 & $0.927-3.174$ & \\
\hline $25-29.9$ & $81(39.3)$ & $35(25.5)$ & 3.226 & $1.775-5.864$ & \\
\hline$\geq 30$ & $44(21.4)$ & $15(10.9)$ & 4.089 & $1.957-8.545$ & \\
\hline Total & 206 Cases & 137 Controls & & & \\
\hline
\end{tabular}

Overall, in both pre-and postmenopausal Kurdish women, breast cancer risk was increased by increasing BMI, but the risk was more pronounced among postmenopausal than pre- menopausal women, especially for women with BMI more than $25 \mathrm{~kg} / \mathrm{m}^{2}$ (see Figure 1). 
The result of multiple logistic regression showed that a high BMI (more than $23 \mathrm{~kg} / \mathrm{m}^{2}$ ) was positively correlated with risk of breast cancer development in both pre- and postmenopausal Kurdish women.

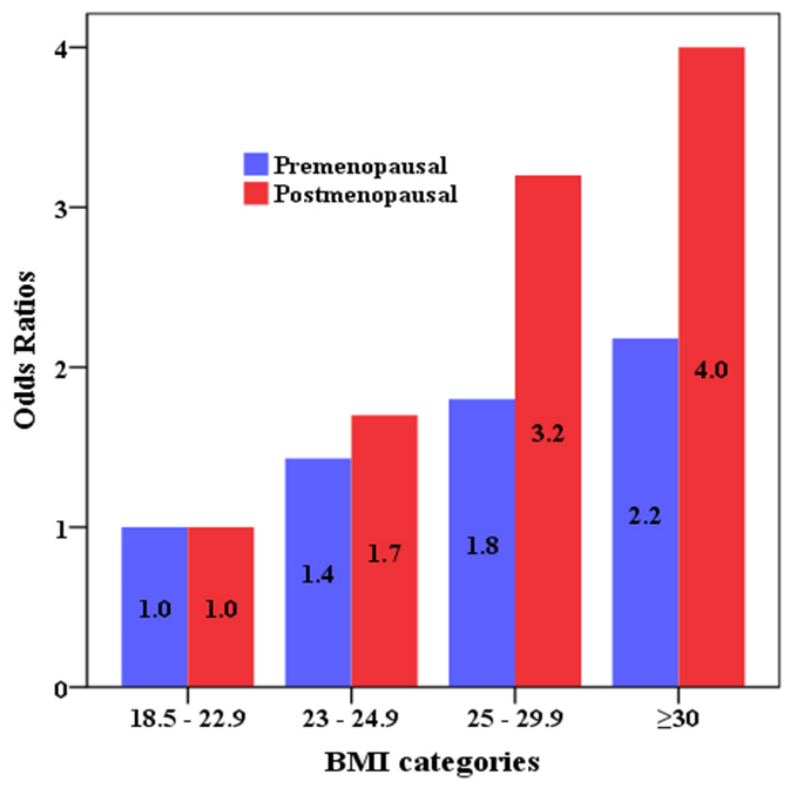

Figure 1. Distribution of Odds Ratios and BMI categories in pre- and postmenopausal breast cancer among Kurdish women (The first BMI category was used as reference)

\section{Discussion}

Because of a relative lack of published studies on breast cancer in Kurdish women, and inconsistent results about the association between BMI and breast cancer in the world, we conducted a case-control study to examine this issue. One of the strengths in this study is that the anthropometric measures of patients were estimated by trained nurses, while for controls by senior house officer of general surgery, which is more meticulous than self-reported measures. Another strength in this study is that which was done in growing area of research.

\subsection{Height and breast cancer}

In our study, we found that there was a significant difference between height of patients with breast cancer for pre- and postmenopausal women collectively and recalculated separately, with controls, which indicates that increased height is associated with a higher risk of breast cancer. This is in accordance with the findings of other studies were done in Europe, Asia, and Africa in which increasing height was associated with an increased risk of breast cancer in both pre- and postmenopausal women. ${ }^{[8,18,21]}$ The final height might be affected by genetic factors, ethnicity, and nutritional lifestyle during periods of growth. Although, the Kurdish womens' height are different from the women in western society and Asia. The increased height seems to be universally associated with increased breast cancer risk. In this paper, the mean height of patients was $161 \mathrm{~cm}$ while the mean height of Asian women is ranging from $154 \mathrm{~cm}-156 \mathrm{~cm} .{ }^{[10]} \mathrm{We}$ have observed that there was a relationship between height and breast cancer irrespective to ethnicity, and genetic factors. Although, the exact mechanism of this relation is not fully understood, but the possible explanation is the fact that energy deprivation in early life decreases mammary tumor rate in animal studies, ${ }^{[8]}$ and adult height may serve as an indicator of childhood or adolescent nutrition. ${ }^{\left[{ }^{8,12]}\right.} \mathrm{We}$ think this relation among Kurdish women could be due to energy deprivation in childhood and adolescence, because Kurdish women who were included in this study born from 1931-1993 might be experienced energy deprivation during period of growth due to economic instability and military conflicts of subsequent wars in Iraq during this period. In developing countries, those have the history of energy deprivation, during childhood and adolescence, increasing height has been associated with increased risk of breast cancer. ${ }^{[21]}$ On the other hand, an earlier growth spurt that might result from better nutrition, which stimulate growth hormone and sex steroid, ${ }^{[8]}$ which leads to growing quickly and mature early. ${ }^{[18]}$ A case-control study demonstrated a link between increased height in childhood and early age of menarche. ${ }^{[10]}$ Really, nutritional status and height may be related to early menarche, but not the sole factor, because our study was included women who were living during economic crisis, but menarche in more than half of females in Iraq starts at age of 10-12 years. ${ }^{[28]}$ Considering postmenopausal women, in whom osteoporosis may cause a decrease in height while the higher level of estrogen is protective against osteoporosis and an established risk factor for breast cancer. ${ }^{[18]}$ Finally, the height is a risk factor for breast cancer irrespective to ethnicity, cultural, genetic, and lifestyle factors. The association between height and breast cancer risk is likely to be a result of a more complex interaction between genetic and environmental factors. ${ }^{[21]}$

\subsection{Weight and breast cancer}

It is well known that the obesity is a risk factor for developing breast cancer. Changes in the diet of Kurdish women (westernization of diet) such as, increased fast food consumption and fatty food intake were contributing in rising BMI, which is a significant risk factor for developing breast cancer. In the present study, we found that there is a significant difference between mean body weight of cases and controls. Our results are similar to the results of studies were conducted throughout the world. ${ }^{[8,13-15,18,23,29-31]}$ This phenomenon might be due to the fact that obesity is associated with insulin resis- 
tance, chronic hyperinsulinemia, increased the bio-activity of Insulin-Like Growth Factor 1 (IGF1), and decrease IGFBinding Protein 1. Insulin was shown to be a growth factor for breast cancer cells. ${ }^{[8,15,18,23,29]}$

In another way, excess body fat was found to be related to a reduction in sex hormone binding proteins, thereby increasing the bio-activity of circulating estrogen. ${ }^{[15]}$

\subsection{BMI and premenopausal breast cancer}

An important finding of our study is that there was a positive association between BMI and risk of breast cancer in premenopausal women. Our result is consistent with the results of studies were done on Korean and African-American women. ${ }^{[11,20]}$ In contrast to the present study, studies in Europe and USA were reported that a high BMI has a protective effect for breast cancer in premenopausal women. ${ }^{[18,19]} \mathrm{A}$ BMI of $25 \mathrm{~kg} / \mathrm{m}^{2}$ is generally accepted as normal (WHO 2000) was used as the cutoff point in most western studies, while in some Asian studies a BMI of $23 \mathrm{~kg} / \mathrm{m}^{2}$ was used as the cutoff point, because of mean BMI is different across the countries. In our study, we were categorized BMI into 5 castes according to both WHO classification and authors' opinion of Asian studies to estimate odds ratios. In this way, we have observed that there was an increased odds ratio by increasing BMI in premenopausal women, but the differences between pre-and postmenopausal women's odds ratios were more for women who had BMI more than $25 \mathrm{~kg} / \mathrm{m}^{2}$ (see Figure 1). Hence, BMI of more than $25 \mathrm{~kg} / \mathrm{m}^{2}$ is a stronger risk factor in postmenopausal than premenopausal women and BMI of more than $23 \mathrm{~kg} / \mathrm{m}^{2}$ is a risk factor (odds ratio more than 1) for breast cancer in both pre-and postmenopausal Kurdish women, thus it is wise to use a BMI of $23 \mathrm{~kg} / \mathrm{m}^{2}$ as cutoff point in Middle-East and Asia. Really, there is a controversy about the effect of BMI on breast cancer risk in premenopausal women. Some prospective studies indicated that the overweight in premenopausal women decreases breast cancer risk due to an increased frequency of anovulatory cycles and decrease circulating estrogen, ${ }^{[8,18,21]}$ but the serum estrogen level may not be the only factor explaining the breast cancer development. One of the limitations in this study is that we have no supporting data on breast cancer risk factors assessment among Kurdish women due to scarce data registry and military conflicts have hampered the studies on breast cancer, but this relationship could be explained by the obesity is associated with chronic hyperinsulinemia, which may also has a mitogenic effects on the breast ductal epithelium, as well as, IGF 1 is also play an important role for breast cancer development. Percentage of body fat correlated positively with serum IGF 1 in premenopausal Japanese women, ${ }^{[8]}$ and hyperinsulinemia may cause breast cancer development. ${ }^{[15,23,28]}$ Furthermore, nutritional factors may partially explain this association in the form of westernization of diet (fast food), which is more common among young Kurdish females, while the elderly women are adopted on the traditional Kurdish diet. On the other hand, the impression of the Iraqi Kurdish physicians who are dealing with obesity and nutrition is that high carbohydrates ingestion in the form of sweets is more common among young Kurdish population than elderly, because type II diabetes is a common disease in elderly Kurdish people. Carbohydrates could influence breast cancer risk potentially by affecting insulin resistance and plasma levels of insulin and glucose. ${ }^{[16]}$ Excessive intake of processed meat and poultry among young people in frequent social, national, religious ceremonies and picnics especially throughout the whole spring and summer of each year might be another cause. There is a strong association between high consumption of processed meat with (ER-/PR-) breast cancer and high consumption of poultry with (ER-/PR+) breast cancer. ${ }^{[17]}$ Another limitation is that we couldn't assess the effect of the ethnicity, which also may play an important role in the potential effect of BMI on premenopausal breast cancer because high BMI may affect breast cancer incidence in different complex causal pathways.

\subsection{BMI and postmenopausal breast cancer}

Findings from the present study suggest that for Iraqi Kurdish women, a high BMI increase breast cancer risk in postmenopausal women and a higher BMI has a higher odds ratio. Our results are consistent with the vast majority of studies were conducted in the world. ${ }^{[8,9,11,15,18,23]}$ Although, this picture was more homogeneous throughout the world for postmenopausal women, little studies have been carried out among Middle-East women. According to our results, there was a significant association between BMI and breast cancer risk in postmenopausal women. A number of hypotheses have been proposed to explain this association including, increase in breast cancer risk may reflect an increase in serum concentration of bioactive estradiol, ${ }^{[8,11,15,26]}$ postmenopausal estrogens are synthesized by peripheral aromatization in adipose tissue. ${ }^{[12,14,18,23]}$ Thus, the obesity increases total body aromatization. ${ }^{[31]}$ Furthermore, the BMI would be strongly associated with risk of estrogen receptorpositive breast cancer. ${ }^{[15,27]}$ Another reason for increased levels of free estrogens in overweight women is the decreased levels of sex hormone binding globulin (SHBG). ${ }^{[1,23]}$ In addition, overweight has been linked with increased insulin levels, insulin resistance, and increased IGF $1 .^{[8,14,18]}$ In summary, the relation of BMI with postmenopausal breast cancer is less conflicting and increased BMI is a risk factor for breast cancer development among postmenopausal 
Kurdish women.

Our results have a clinical implication for achieving a good dietary program aimed toward body weight reduction in Kurdish women, which may regard as a measure for breast cancer prevention. We suggest doing more research on this topic including assessment of other risk factors, and some fundamental histopathological variables such as tumor size, grade, stage, and the effect of BMI on these variables.

\section{Conclusion}

Among the Iraqi Kurdish population, height, weight, and body mass index are associated with increased breast cancer risk. There is a positive association between BMI and breast cancer risk for both pre- and postmenopausal women, but the association is stronger among postmenopausal women.

\section{REFERENCES}

[1] Issac D. Gukas, Barbara A. Jennings, Barnabas M. Mandong, et al. A comparison of the pattern of occurrence of breast cancer in Nigeria and British women. The Breast. 2006; 15: 90-95. PMid: 16473740. http://dx.doi.org/10.1016/j.breast. 2005.02 .003

[2] Mohammad Sorowar Hossain, Shameema Ferdous, Henrike E. Karim-Kos. Breast cancer in South Asia: A Bangladeshi perspective. Cancer Epidemiology. 2014; 38: 465-470. PMid: 25182670. http://dx.doi.org/10.1016/j.canep. 2014.08.004

[3] Daniel J, Jocelyn E. Finlay, Subramanian SV. Weight of communities: A multilevel analysis of body mass index in 32,814 neighborhoods in 57 low- to middle-income countries (LMICs). Social Science \& Medicine. 2012; 75: 311-322. PMid: 22541801. http://dx.doi.org/10.1016/j.socscimed.2012.02.014

[4] Toshiaki Iwase, Rikiya Nakamura, Naohito Yamamoto, et al. The effect of molecular sub-type and body-mass index on neo-adjuvant chemotherapy in breast cancer patients. The breast. 2014; 23: 264 272. PMid: 24530096. http://dx.doi.org/10.1016/j.breas t. 2013.11.008

[5] Mariel M Finucane, Gretchen A Stevens, Melanie J Cowan, et al. National, regional, and global trends in body mass index since 1980: systematic analysis of health examination surveys and epidemiological studies with 960 country-years and 9.1 million participants Lancet. 2011; 377: 557-567. http://dx.doi.org/10.1016/S01 40-6736(10)62037-5

[6] Woo J, Arai H, Ng TP, et al. Ethnic and geographic variations in muscle mass, muscle strength and physical performance measures. European Geriatric Medicine. 2014; 5: 155-164. http://dx.doi .org/10.1016/j.eurger.2014.04.003

[7] Nazleen Bharmal, Robert M. Kaplan, Martin F. Shapiro, et al. The association of religiosity with overweight/obese body mass index among Asian Indian immigrants in California. Preventive Medicine. 2013; 57: 315-321. PMid: 23769898. http://dx.doi .org/10.10 $16 / j \cdot$ ypmed. 2013.06 .003

[8] Motokoy Iwasaki, Tetsuya Otani, Manami Inoue, et al. Body Size and Risk for Breast Cancer in Relation to Estrogen and Progesterone Receptor Status in Japan. Ann Epidermiol. 2007; 17: 304-312. PMid: 17174568. http://dx.doi.org/10.1016/j.annepidem. 2006. 09.003

[9] Louis W.C. Chow, Ka Luen Lui, Johnny Chun Yin Chan, et al Association Between Body Mass index and Risk of Formation of Breast Cancer in Chinese Women. Asian J Surg. 2005; 28: 179-184. http://dx.doi .org/10.1016/S1015-9584(09)60338-9

[10] Christine L Parr, David G Batty, Tai Hing Lam, et al. Body mass index and cancer mortality in the Asia-Pacific Cohort Studies Collaboration: pooled analyzes of 424,519 participants. Lancet Oncol.
2010; 11: 741-752. http://dx.doi.org/10.1016/S1470-204 5 (10) $70141-8$

[11] Dukyoo Jung, Sun-Mi Lee. BMI and Breast Cancer in Korean Women: A Meta-Analysis. Asian Nursing Research. 2009; 3: 31-40. http://dx.doi.org/10.1016/S1976-1317(09)60014-1

[12] Per Eystein Lonning, Benjamin P. Haynes, Mitch Dowsett. Relationship of body mass index with aromatization and plasma and tissue oestrogen levels in postmenopausal breast cancer patients treated with aromatase inhibitors. European Journal of Cancer. 2014; 50: 1055-1064. PMid: 24507547. http://dx.doi.org/10.1016/j .ejca.2014.01.007

[13] Penelope J. Robinson, Robin J. Bell, Susan R. Davis. Obesity is associated with a poorer prognosis in women with hormone receptorpositive breast cancer. Maturitas. 2014; 79(3): 279-286. PMid: 25088248. http://dx.doi.org/10.1016/j.maturitas. 2014. 07.004

[14] Lisa Gallicchio, Meghan A. McSorley, Craig J. Newschaffer, et al. Body mass, polymorphism in obesity-related genes, and the risk of developing breast cancer among women with benign breast disease. Cancer Detection and Prevention. 2007; 31: 95-101. PMid: 17428620. http://dx.doi.org/10.1016/j.cdp. 2007 . 02.004

[15] Rosilene Lima Pinheiro, Luis OtavioSarian, Aarao Mendes PintoNeto, et al. Relationship between body mass index, waist circumference, and waist to hip ratio and the steroid hormone receptor status in breast carcinoma of pre- and postmenopausal women. The Breast. 2009; 18: 8-12. PMid: 19041243. http://dx.doi.org/10.1016 /j.breast. 2008.09.001

[16] Veronique Chajes, Isabelle Romieu. Nutrition and breast cancer. Maturitas. 2014; 77: 7-11. PMid: 24215727. http://dx.doi.org/1 $0.1016 /$ j.maturitas. 2013.10.004

[17] Valentina Rosato, Paola Bertuccio, Cristina Bosetti, et al. Nutritional factors, physical activity, and breast cancer by hormonal receptor status. The Breast. 2013; 22: 887-893. PMid: 23643804. http://dx.doi.org/10.1016/j.breast.2013.04.004

[18] Cold S, Hansen S, Overvad K, et al. A Woman's build and the Risk of breast Cancer. European Journal of Cancer. 1998; 34: 1163-1174. http://dx.doi .org/10.1016/S0959-8049(97)10167-8

[19] Heather J. Baer, Shelley S. Tworonger, Susan E. Hankinson, et al. Body Fatness at Young Ages and Risk of Breast Cancer Throughout Life. American Journal of Epidemiology. 2010; 171: 1183-1194. PMid: 20460303. http://dx.doi.org/10.1093/aje/kwq045

[20] Kangmin Zhu, Joanne Caulfield, Sandra Hunter, et al. Body Mass Index and Breast Cancer Risk in African American Women. Ann Epidemiol. 2005; 15: 123-128. PMid: 15652717. http://dx.doi .org/10.1016/j. annepidem. 2004.05.011 
[21] Clement A. Adebamowo, Temidayo O. Ogundiran, Adeniyi A. Adeipekun, et al. Obesity and Height in Urban Nigerian Women with Breast Cancer. Ann Epidemiol. 2003; 3: 455-461. http: //dx.doi.org/10.1016/S1047-2797(02) 00426-X

[22] Olsson A, Garne JP, Tengrup I, et al. Body mass index and breast cancer survival in relation to the introduction of mammographic screening. EJSO. 2009; 35: 1261-1267. PMid: 19481409. http: //dx.doi.org/10.1016/j.ejso.2009.04.012

[23] Carmichael AR, Bates T. Obesity and breast cancer: a review of the literature. The Breast. 2004; 13: 85-92. PMid: 15019686. http://dx.doi.org/10.1016/j.breast.2003.03.001

[24] Seraina Margaretha Schmid, Monika Eichholzer, Florence Bovey, et al. Impact of body mass index on compliance and persistence to adjuvant breast cancer therapy. The Breast. 2012; 21: 487-492. PMid: 22153572. http://dx.doi.org/10.1016/j.breast.2011.11. 005

[25] Pamela J. Goodwin. Obesity and endocrine therapy: Host factors and breast cancer outcome. The Breast. 2013; 22: 544-547. PMid: 24074791. http://dx.doi.org/10.1016/j. breast. 2013.07 . 008

[26] Aspinall SR, Cook DB, Shenton BK, et al. Serum adrenal androgens in women with primary operable breast cancer and their relationship with age and body mass index. The Breast. 2003; 12: 63-71. http://dx.doi.org/10.1016/S0960-9776(02)00264-3
[27] Amanda I. Phipps, Diana SM. Buist, Kathleen E. Malone, et al Breast Density, Body Mass Index, and Risk of Tumor Marker-Defined Subtypes of Breast Cancer. Ann Epidemiol. 2012; 22: 340-348. PMid: 22366170. http://dx.doi.org/10.1016/j. annepidem. 2012. 02.002

[28] Nada AS. Al-Alwan, Farah LR. Al-Rufaee. Comparative demographic and clinicopathological study on the behavior of mammary carcinoma in three Iraqi governorates (Baghdad, Hilla and Karbala). J Fac Med Baghdad. 2010; 52: 419.

[29] Made Wenten, Frank D. Gilliand, Kathy Baumgartner, et al. Association of Weight, Weight Change, and Body Mass with Breast Cancer Risk in Hispanic and Non-Hispanic White Women. Ann Epidemiol. 2002; 12: 435-444. http://dx.doi.org/10.1016/S1047-279 7 (01) 00293-9

[30] Stark A, Schultz D, Kapke A, et al. Obesity and risk of the less commonly diagnosed sub-types of breast cancer. EJSO. 2009; 35: 928-935. PMid: 19121564. http://dx.doi.org/10.1016/j.e jso. 2008.11.009

[31] Li-Ni Liu, Christine Miaskowski, Jong-Shyan Wang, et al. Accuracy of body mass index to determine obesity in women with breast cancer: An observational study of Taiwanese sample. International Journal of Nursing Studies. 2010; 47: 994-1000. PMid: 20129610. http://dx.doi.org/10.1016/j.ijnurstu.2010.01.002 